\begin{tabular}{c} 
Volume and Issues Obtainable at Center for Sustainability Research and Consultancy \\
Journal of Business and Social Review in Emerging Economies \\
ISSN: 2519-089X (E): 2519-0326 \\
Volume 6: No. 1, March 2020 \\
CSRᄃ \\
Journal homepage: www.publishing.globalcsrc.org/jbsee \\
\hline
\end{tabular}

\title{
Pakistani High Performing and Low Performing Secondary School Science Students' Beliefs about Ability to Learn Science
}

\section{${ }^{1}$ Rafaquat Ali, ${ }^{2}$ Syed Zubair Haider, ${ }^{3}$ Uzma Munawar}

${ }^{1}$ Assistant Professor, Department of Education, Bahawalnagar Campus, Bahawalnagar, The Islamia University of Bahawalpur, Punjab, Pakistan: rafaquatiub@yahoo.com

${ }^{2}$ Assistant Professor, Department of Educational Training, The Islamia University of Bahawalpur, Punjab,

Pakistan: zubairiub@hotmail.com

${ }^{3}$ Assistant Professor, Department of Education, Govt Sadiq College Women University, Bahawalpur,

Punjab, Pakistan: ain_mem@yahoo.com

\begin{tabular}{l} 
ARTICLE DETAILS \\
\hline History \\
Revised format: February 2020 \\
Available Online: March 2020 \\
\hline Keywords \\
Personal Epistemology, \\
Epistemic Climate In Pakistani \\
Classrooms, Learnability \\
Beliefs, Science Students, \\
Pakistani Public Schools
\end{tabular}

JEL Classification:

I0, D83, D8

\section{ABSTRACT}

Beliefs of ability to learn are identified as a key dimension of students' epistemological beliefs. These beliefs can range from the ability to learn is innate, unchanging to the ability to learn is not innate, changing and improvable. These beliefs are acknowledged as the principal predictor for students' effort to learn, learning strategies and motivational behaviour in school learning. The current study discovered the nature of Pakistani science students' beliefs about ability to learn. The qualitative approach was chosen and students were purposefully selected from two sections of 9th grade of a public secondary school for focus group interviews. These students were identified as above average and below average performing students. Students' excerpts about their beliefs of ability to learn revealed noticeable differences in students' beliefs of ability to learn with regard to their association with above average and below average performing students' groups. The patterns visible in opinions of students from below average performing group were naive beliefs of ability to learn. The results are discussed in perspective of sampling characteristics and there are recommendations suggested to improve teaching learning situations in Pakistani schools.

Corresponding author's email address: zubairiub@ hotmail.com

Recommended citation: Ali, R., Haider, S. Z. \& Munawar, U. (2020). Pakistani High Performing and Low Performing Secondary School Science Students' Beliefs About Ability to Learn Science. Journal of Business and Social Review in Emerging Economies, 6(1), 177-186

DOI: $10.26710 / j b s e e . v 6 i 1.1036$

\section{Introduction}

Our beliefs are reflected in our various life routines. Equally, our beliefs about the nature, development and structure of knowledge, speed and ability of learning called epistemological beliefs resonate in our 
learning behaviour (Schommer-Aikins, 2004). A learner's learning behaviour and learning outcomes depend on learner's epistemological beliefs (Chen \& Pajares, 2010; Lodewyk, 2007; McBeth, 2010) regardless it is formal, informal or non-formal learning situation (Hofer, 2002). It is established that epistemological beliefs direct and regulate students' academic performance, learning goals of a learning task (Harris, 2003), effort to learn, decision to allocate time for learning (Corte et al., 2002), text comprehension (Schommer, 1989), cognitive development (Bird, 2005), and use of cognitive processing strategies (Almahasneh, 2006; Buehl, 2003). In short, epistemological beliefs steer and direct learners' cognitive and affective learning resources, which result in display of certain learning behaviours and learning approaches (Entwistle \& Peterson, 2004).

Although, there exists an evidence that epistemological beliefs are general, context free and domain/discipline independent (Schommer-Aikins et al., 2003). The students of different disciplines and contexts are reported to have differences in epistemological beliefs (Hofer, 2000; Muis et al., 2006). As a result, it is deducible that students might have domain general epistemological beliefs beside the domain specific beliefs (Buehl et al., 2002). Conspicuously, it is the duration or length of students' educational experience in a specific field of study that inculcates domain specific epistemological beliefs (SchommerAikins et al., 2003). The domain specific teaching practices in classrooms and the nature of that discipline's content might root the domain specific epistemological beliefs among students (Hofer, 2002; Hofer, 2006; Schommer-Aikins et al., 2003).

A learner's epistemological beliefs consist different dimensions. Schommer-Aikins (2004) proposed six dimensions of epistemological beliefs, which are the beliefs about stability of knowledge (knowledge is unchanging to knowledge is evolving), structure of knowledge (knowledge is found as isolated parts to knowledge is organized, and interlinked), source of knowledge (the source of knowledge is authority to logic and empirical evidence is the source of knowledge), speed of knowledge development (knowledge is suddenly acquired to knowledge acquisition is gradual) and the ability to learn (ability to learn is fixed, innate to ability to learn is improvable). Among these beliefs, the belief about ability to learn is a general and domain independent belief (Schommer-Aikins, 2004). Ability to learn beliefs are important and crucial in the sense that these beliefs provide substance for the development of other dimensions of epistemological beliefs. Students' beliefs about knowledge stability, structure, source, and speed develop after the development of beliefs about the ability of learning (Schommer-Aikins et al., 2000).

Therefore, the comprehensive understanding of students' beliefs of ability to learn is pertinent for understanding of their epistemological beliefs and the quality of their learning outcomes (SchommerAikins et al., 2010). In another way, one's beliefs of ability to learn and beliefs of knowledge complement each other (Kienhues \& Bromme, 2011). In an integrated fashion, a learner's beliefs of knowledge and ability to learn and other aspects of learner's cognitive learning reconcile each other. For that reason, it is relevant to understand students' beliefs of knowledge and beliefs of learning to fathom the way students use different cognitive resources (De-Corte et al., 2010).

Dweck (2002) found that beliefs of ability to learn demarcate student's level of effort, performance, and notably, these beliefs delineate students' motivation for a learning tasks. The beliefs of ability to learn influence students' learning goals in a learning task, and consequently, students try to understand the learning text to secure their anticipated level of understanding (Dweck \& Leggett, 1988). It is credible to accept that students' beliefs of ability to learn regulate students' expectations from themselves, and the learning task during their interactions to learning situations. The students' belief that ability to learn is fixed negatively impact their motivation, however, students' belief that ability to learn is improvable is positively linked to students' intrinsic motivation, confidence, valuing a learning task and control over learning (Paulsen \& Feldman, 2005). Likewise, beliefs of ability to learn have shown an association with the way we process any knowledge and information (Kienhues \& Bromme, 2011). 
The students who perceive that their level of ability to learn is low, and they hold the belief that human ability to learn is innate, and fixed, such students found themselves helpless, avoid challenges and have low persistence for academic tasks (Dweck \& Leggett, 1988). These all consequence in their poor academic performance (Schommer-Aikins et al., 2000). These students if get negative feedback about their performance, they become demotivated (Dweck, 2002). Thus, negative feedback detrimentally impact their future performance. In this scenario, the individual implicit ability or attribution theories are capable to help us to understand by what means two individuals understand the learning text differently in a same learning situation, although they have the same ability (Dweck \& Leggett, 1988). It seems that students' beliefs of ability to learn influence all aspects of students' learning behavior at schools. These beliefs of ability to learn offer a way to understand students' academic performance, motivation, regulation of learning and strategies to learn etc. However, these beliefs depend on the culture (Schommer-Aikins et al., 2010), parents' attitude towards their children (Schommer, 1993), and education system of a society (De Corte et al., 2010; Muis, 2004).

There is limited research on Asian students' epistemological beliefs and learning. There exists no empirical evidence about Pakistani students' beliefs of learning and knowledge. Because the beliefs of learning and knowledge depend on the culture and education system of any nation, it is pertinent to study beliefs of learning of Pakistani students so that it becomes possible to understand Pakistani students' high failing rate, poor academic performance, inadequate learning behaviors and rote learning. Moreover, conceptions of learning and beliefs of learning are interrelated. Hence, the naive, less developed and less advanced conceptions of learning of Pakistani students (Ali et al., 2018) can be best understood through exploring their epistemological beliefs. Additionally, there is no suitable questionnaire of epistemological beliefs in Urdu language. Therefore, it was apropos to use the qualitative approach in current study to probe Pakistani students' epistemological beliefs related to learning.

\section{Materials and Method}

\subsection{Population and Sample Selection}

The current study explored the secondary school science students' beliefs of ability to learn. In the nonprobability sampling method, the purposive sampling technique was used and volunteers were selected to probe their beliefs of ability to learn. The focus group interviews were used to collect information about students' beliefs of ability to learn. All selected students were from one public school and all students were male. Eight groups of students were selected for focus group interviews. Each group of students comprised six students. These groups were from two sections of the school; the English medium section and the Urdu medium section. According to school policy, the students who performed above average in the last examination were allowed to be enrolled in the English medium section. However, the students who performed below average in their last examination were permitted to be enrolled in the Urdu medium section. Four focus group interviews were from the students of above average performing English medium section of the school. As well, there were four focus group interviews from the below average performing Urdu medium section of the school. Both groups were of science students.

\subsection{Data Collection}

The focus group interviews were conducted in Urdu language. Initially, these interviews were transcribed in Urdu language. Later on, these interview transcriptions were translated into the English language for the international audience. The following questions were enquired to explore students' thoughtfulness of their beliefs of ability to learn:

- Do you think one's ability to learn science is fixed or improvable?

- Why do you think that ability to learn science is/is not fixed?

- How can one's ability to learn science can or cannot improve?

- Why someone is/is not able to learn certain things in certain periods of life?

\subsection{Data Analysis}


The interview transcripts were analyzed with the help of NVivo 10. The qualitative data were read again and again to understand and construe students' verbatim into themes and subthemes. The researchers used the data driven approach in thematic analysis. The themes emerged were classified into appropriate categories. The researchers discussed the themes that emerged with each other, and with their other peers. This is called peer debriefing (Ely, 1991), which can assure that the research findings and the process is unbiased and trustworthy. The researchers included suggestions by their peers in different phases of this study such as during the process of data collection, interview schedule development and theme development.

\section{Results}

The students' views related to the ability to learn befall into two basic themes. These themes have obvious differences in their intensity across students from above average performing students' groups and below average performing students' groups (Figure 1).

1. Ability to learn is innate

2. Ability to learn in not fixed

The students' views about the ability to learn is not innate were further classified into the following subthemes

2.1 Ability to learn is improvable by an increase in subject knowledge and knowledge of learning strategies

2.2 Ability to learn changes automatically with change in age and time

$2 . .3$ Interest, hard work and willpower can change ability to learn.

The excerpt's source indicated as AAPS means that the student is from above average performing groups. On the other hand, the abbreviation BAPS means the student is from below average performing groups of students.

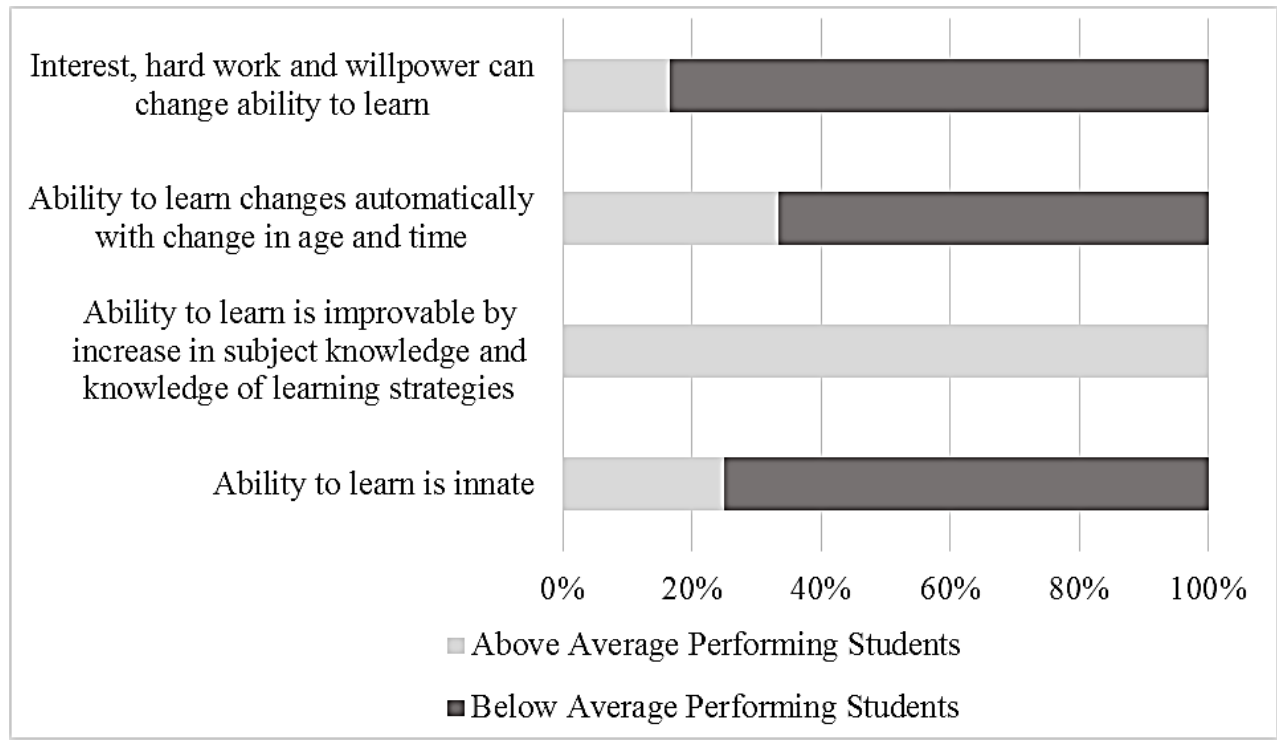

Figure 1: Beliefs of Ability to Learn in High and Below Average Performing Students

\subsection{Ability to Learn is Innate}

The theme about belief that ability to learn is innate was evident in passages from both above average performing students and below average performing students. However, the number of students who believed that ability to learn is fixed were minimum from above average performing English medium 
section as compared to below average performing Urdu medium section. These students hold the belief that the ability to learn is innate and is fixed. They believe that it is not possible for someone to control or change their ability of learning. These students tried to justified their beliefs by arguing examples from the surrounding world and from their other beliefs. In the following excerpt, a student argues that what someone can learn is by destiny, and humans take and acquire which is in their destiny.

"The ability, which God bestow to humans, remains same, and a man thinks with his mind which is bestowed to him (BAPS)."

Moreover, these students have a belief that ability to learn is different among individuals, however, someone's individual ability to learn is fixed and static. This belief set the foundation of students' excuse of their failure to learn.

"Everyone learns according to his or her own ability, and some learn more and some learn less (AAPS)."

The belief that ability to learn is innate might have different consequences for students who are high achievers and the low achievers. The high achievers might have a higher level of their perceived ability to learn as compared to the low achievers who might perceive their ability to learn of low level.

\subsection{Ability to Learn in not Fixed}

The belief that ability to learn is not innate was the most conspicuous belief about learnability in most above average performing students and below average performing students. However, the deeper investigation to distinguish students' beliefs about the reasons for unfixed and changing ability to learn exposed different views among students of above average performing English medium section and below average performing Urdu medium section (Figure 1). These views can be grouped under three sub-themes as below:

2.1. Ability to learn is improvable by an increase in subject knowledge and knowledge of learning strategies

2.2. Ability to learn changes automatically with change in age and time

2.3. Interest, hard work and willpower can change ability to learn

\subsection{Ability to learn is improvable by an increase in subject knowledge and knowledge of learning strategies}

The belief 'ability to learn is improvable by an increase in subject knowledge and knowledge of learning strategies' was the belief only present in above average performing students of English medium groups (Figure 1). This belief is important in a sense that these students appreciate that by an increase in knowledge of subject and learning, someone can control his/her learning. These students tackle and face challenges that they think can increase their ability to learn. These students appear to have mastery goal orientation.

\footnotetext{
"Everyone can learn, but they should know how to learn it? (AAPS)."

"Some use this (ability to learn), and some do not use this because of lack of subject knowledge and ways to learn. This ability to learn changes with the passage of time (AAPS)."
}

These students' thoughts about their beliefs in ability to learn have traces of discussion about the role of nature and nurture in learning. One student appreciated the role of parents and resources to improve students' ability to learn. 
"It (the ability to learn) is not stable. However, parents and teachers have a much more important role in this ability. If parents and teachers help us to learn in a good way, then we will not have any difficulty in learning anything (AAPS).”

\subsection{Ability to learn changes automatically with change in age and time}

There existed a belief that there is a self-change in ability to learn because of age and time. The holders of this belief were from both the above average performing English medium section as well as from the below average performing Urdu medium section. However, the students who hold this belief were more from the below average performing Urdu medium section. These students look like to hold a belief that a person will be able to learn anything after he/she will reach a certain age. According to them ability to learn was uncontrollable or un-improvable, and an individual cannot control or improve it by themselves. Although, human ability to learn increases with an increase in age, however, for these students it might be an excuse for their poor performance. This point of view appears non-humanistic view, In which humans appear helpless and unable to control their ability to learn.

"It (ability to learn) changes with time. As much as time changes, it also changes (BAPS)."

"Just take the example of a child, when he is young, then he cannot even walk, when grow older, he learns to walk and soon he starts to run. The ability to learn likewise changes (AAPS)."

"We were young, and then we have different kind of thinking, and different ability to learn. When we were young we learn to ride bicycles, and now we have learned to drive a motorbike. Therefore, it (ability to learn) changes along the change in time (BAPS)."

\subsection{Interest, hard work and willpower can change ability to learn}

The students' belief that someone's interest, hard work and willpower can change someone's ability to learn seems rooted in muscular concept of intelligence, which assumes the human mind to be like a muscle. These students think that they can increase their ability to learn only by an increase in effort. Most of the students who hold this belief were from the below average performing Urdu medium section. It seems they were forced to choose subjects, and their parents and teachers consistently hard-press them for hard work and to take interest in science.

"If, we try or remain trying then we can read more than our capacity or ability (BAPS)."

"If, someone will do a lot of hard work, and will do good deeds throughout of his life, the ability to learn will increase... (BAPS)."

"If, a man work hard and do effort, then he can understand everything (BAPS).”

\section{Discussion}

The findings of prior studies that high performing students have a belief that ability to learn is improvable and low performing students believe that ability to learn is fixed (Schommer-Aikins et al., 2000) were acknowledged in this study. High performing students are found to believe that by knowledge of learning strategies and the learning process they can improve their ability to learn.

Similarly, the results of this study indicated the existence of naive belief about ability to learn 'ability to learn is innate' in most of the below average performing students and in few above average performing students. The presence of this naive belief is not ideal for students of both groups. In case of high performing students if they will fail in any learning task, and they get negative feedback, it is expected that it will damage their self-belief, and consequently their motivation to learn will decrease (Dweck, 
2002). However, it might be very detrimental for low performing students. Because it will affect their motivation, and they will avoid even to try something, which they think is beyond their ability to learn. These students feel helpless and fail to persist when they face difficult tasks (Schommer-Aikins, 2004). This naive belief is negatively associated to intrinsic and extrinsic motivational strategies, self-efficacy, and control of learning (Paulsen \& Feldman, 2005). The harms of naive belief "ability to learn is innate" mount up when it teams up with other naive beliefs. The students draw simplistic and quick conclusions of the problems if they have naive belief that ability to learn is by birth and naive belief that knowledge is simple (Schommer \& Dunnell, 1997).

The below average performing students who believe that willpower, hard work and interest can change their ability to learn construed learning as the capacity which means that by an increase in the effort they can enhance their performance to a certain level (Nicholls, 1990). However, the willpower, and hard work depend on the persistence which depends on the sophisticated belief that ability to learn is improvable (Dweck \& Leggett, 1988). If someone thinks ability is something related to hard work, and he/she doubt his/her ability to success in a learning task, then the hard work may turn out less attractive to him/her (Nicholls, 1990). These students consider ability as the effort to apply and they think students doing hard work are more able (Nicholls, 1990). According to Tait (2009) such students have an inexact understanding of their own capability and competence. This belief of ability to learn is related to shallow learning (Young, 2005).

The students' naive belief in ability to learn is associated to students' naive conceptions of learning (Entwistle \& Peterson, 2004; Schommer-Aikins et al., 2000) and use of memorization strategies (Schommer-Aikins et al., 2000). Likewise, the sample of the study were from low socioeconomic class. Consequently, the results of this study rationally explain the presence of naive conceptions of learning, memorization and rehearsal in Pakistani low socioeconomic class students (Ali \& Abou, 2019; Ali et al., 2018). Likewise, the sample comprised only male students in this study, and the male students are more likely to have naive beliefs of ability to learn (Paulsen \& Wells, 1998).

The role of the school is very critical in the development of epistemological beliefs. Teachers' instruction is ingrained in their epistemological beliefs (Fives \& Buehl, 2010). Traditional teaching methods exist in Pakistani secondary school education (Malik, 2012), which coerce students to quickly memorise facts, and structured text, and consequently, the students develop the belief that ability to learn is innate beside other naive epistemological beliefs (Muis, 2004).

\section{Recommendations}

The current study leads to the following recommendations:

- Constructivist teaching approaches should be encouraged in Pakistani secondary schools to counter the disadvantages of naive epistemological beliefs.

- There is no study about the Pakistani teachers' epistemological beliefs. Teachers' epistemological beliefs should be explored to understand epistemic climate of Pakistani classrooms.

- Interventions should be designed to help students who have naive epistemological beliefs.

\section{References}

Ali, R., \& Abou, B. (2019). The Probability to Memorize and Understand Textbook Information: Socioeconomic Class as the Predictor for Cognitive Processing Strategies in Pakistani Education System. Pakistan Journal of Social Sciences, 39(1), $253-270$. Retrieved from https://www.bzu.edu.pk/PJSS/Vol.\%2038,\%20No.\%202,\%202018

/Vol.\%2039,\%20No.\%201,\%202019/PJSS-Vol39-No1,\%202019-21.pdf

Ali, R., Khurshid, K., Shahzad, A., Hussain, I., \& Abu Bakar, Z. (2018). Nature of Conceptions of Learning in a Collectivistic Society: A Qualitative Case Study of Pakistan. Eurasia Journal of Mathematics, Science and Technology Education, 14(4), 1175-1187. doi:10.29333/ejmste/81867 
Almahasneh, R. (2006). The effects of beliefs about knowledge and learning on students' self-regulated studying. (NR23881 Ph.D.), Simon Fraser University (Canada), Ann Arbor. Retrieved from https://vpn.utm.my/docview/304941702?accountid=41678 ProQuest Dissertations \& Theses Global database.

Bird, M. (2005). Linking epistemological beliefs to cognitive development and academic performance. (1436547 M.Ed.), Wichita State University, Ann Arbor. Retrieved from https://vpn.utm.my/docview/305385367?accountid=41678 ProQuest Dissertations \& Theses Global database.

Buehl, M. M. (2003). At the crossroads of epistemology and motivation: Modeling the relations between students' domain-specific epistemological beliefs, achievement motivation, and task performance. (3107202 Ph.D.), University of Maryland, College Park, Ann Arbor. Retrieved from https://vpn.utm.my/docview/305319754?accountid=41678 ProQuest Dissertations \& Theses Global database.

Buehl, M. M., Alexander, P. A., \& Murphy, P. K. (2002). Beliefs about Schooled Knowledge: Domain Specific or Domain General? Contemporary Educational Psychology, 27(3), 415-449. doi:http://dx.doi.org/10.1006/ceps.2001.1103

Chen, J. A., \& Pajares, F. (2010). Implicit theories of ability of Grade 6 science students: Relation to epistemological beliefs and academic motivation and achievement in science. Contemporary Educational Psychology, 35(1), 75-87. doi:http://dx.doi.org/10.1016/j.cedpsych.2009.10.003

Corte, E. D., Eynde, P. O. t., \& Verschaffel, L. (2002). Knowing What toBelieve:The Relevance of Students' Mathematical Beliefs for Mathematics Education. In B. K. Hofer \& P. R. Pintrich (Eds.), Personal Epistemology:The Psychology of BeliefsAbout Knowledge and Knowing (pp. 297-320). New Jersey: Lawrence Erlbaum Associates, Inc.

De-Corte, E., Op 't Eynde, P., Depaepe, F., \& Verschaffel, b. (2010). The reflexive relation between students' mathematics-related beliefs and the mathematics classroom culture. In L. D. Bendixen \& F. C. Feucht (Eds.), Practice (pp. 292-327). Cambridge: Cambridge University Press.

De Corte, E., Op 't Eynde, P., Depaepe, F., \& Verschaffel, L. (2010). The reflexive relation between students' mathematics-related beliefs and the mathematics classroom culture. In L. D. Bendixen \& F. C. Feucht (Eds.), Personal Epistemology in the Classroom: Theory, Research, and Implications for Practice. Cambridge: Cambridge University Press.

Dweck, C. S. (2002). The Development of Ability Conceptions. In A. Wigfield \& j. S. Eccles (Eds.), Development of Achievement Motivation (pp. 57-83). London: Academic Press.

Dweck, C. S., \& Leggett, E. L. (1988). A social-cognitive approach to motivation and personality. Psychological Review, 95(2), 256-273. Retrieved from https://nebula.wsimg.com/97f218cc2e65c9504318375ea0f175b4?AccessKeyId=F3B15443490188 2AEC56\&disposition=0\&alloworigin $=1$

Ely, M. (1991). Doing Qualitative Research: Circles Within Circles/Margot Ely with Margaret Anzul, Teri Friedman, Diane Garner, Ann McCormack Steinmetz. Philadelphia: The Falmer Press, Taylor \& Francis Inc.

Entwistle, N. J., \& Peterson, E. R. (2004). Conceptions of learning and knowledge in higher education: Relationships with study behaviour and influences of learning environments. International Journal of Educational Research, 41(6), 407-428. doi:http://dx.doi.org/10.1016/j.ijer.2005.08.009

Fives, H., \& Buehl, M. M. (2010). Teachers' articulation of beliefs about teaching knowledge: conceptualizing a belief framework. In L. D. Bendixen \& F. C. Feucht (Eds.), Personal Epistemology in the Classroom: Theory, Research, and Implications for Practice (pp. 470-515). Cambridge: Cambridge University Press.

Harris, C. L. (2003). Understanding the role of epistemological beliefs in post-graduate studies: Motivation and conceptions of learning in first-year law students. (3116082 Ph.D.), The University of Texas at Austin, Ann Arbor. Retrieved from https://vpn.utm.my/docview/305307926?accountid=41678 ProQuest Dissertations \& Theses Global database.

Hofer, B., K. (2002). Personal Epistemology as a Psychological and Educational Construct:An 
Introduction. In B. K. Hofer \& P. R. Pintrich (Eds.), Personal Epistemology:The Psychology of Beliefs About Knowledge and Knowing. New Jersey: Lawrence Erlbaum Associates, Inc.

Hofer, B. K. (2000). Dimensionality and Disciplinary Differences in Personal Epistemology. Contemporary Educational Psychology, 25(4), 378-405. Retrieved from http://www.scopus.com/inward/record.url?eid=2-s2.0-0000582040\&partnerID= 40\&md5=844f7015a98cefc706cb5f03f920ad10

Hofer, B. K. (2006). Domain specificity of personal epistemology: Resolved questions, persistent issues, new models. International Journal of Educational Research, 45(1-2), 85-95. doi:http://dx.doi.org/10.1016/j.ijer.2006.08.006

Kienhues, D., \& Bromme, R. (2011). Beliefs About Abilities and Epistemic Beliefs: Aspects of Cognitive Flexibility in Information-Rich Environments. In J. Elen, E. Stahl, R. Bromme, \& G. Clarebout (Eds.), Links Between Beliefs and Cognitive Flexibility: Lessons Learned (pp. 105-124). London: Springer Science+Business Media.

Lodewyk, K. R. (2007). Relations among Epistemological Beliefs, Academic Achievement, and Task Performance in Secondary School Students. Educational Psychology, 27(3), 307-327. doi:10.1080/01443410601104080

Malik, A. H. (2012). A Comparative Study of Elite-English-Medium Schools, Public Schools, and Islamic Madaris in Contemporary Pakistan: The Use of Pierre Bourdieu's Theory to Understand "Inequalities in Educational and Occupational Opportunities". (Ed.D. Thesis), University of Toronto, Canada. Retrieved from https://vpn.utm.my/docview/1349629172?accountid=41678 ProQuest Dissertations \& Theses Full Text database. (NR97041)

McBeth, M. (2010). The relationship between epistemological beliefs, learning strategies and achievement in higher education. (3439623 Ed.D.), Northern Illinois University, Ann Arbor. Retrieved from https://vpn.utm.my/docview/851700131 ?accountid=41678 ProQuest Dissertations $\&$ Theses Global database.

Muis, K., R, Bendixen, L., D, \& Haerle, F., C. (2006). Domain-Generality and Domain-Specificity in Personal Epistemology Research: Philosophical and Empirical Reflections in the Development of a Theoretical Framework. Educational Psychology Review, 18(1), 3-54. doi:10.1007/s10648-0069003-6

Muis, K. R. (2004). Personal Epistemology and Mathematics: A Critical Review and Synthesis of Research. Review of Educational Research, 74(3), 317-377. doi:10.3102/00346543074003317

Nicholls, G. (1990). What is ability and why are we mindful of it? A developmental perspective. In R. I. Sternberg \& Kolligian (Eds.), Competence considered (pp. 11-40). New Haven, CT: Yale University Press.

Paulsen, M., \& Wells, C. (1998). Domin Differences in the Epistemological Beliefs of College Students. Research in Higher Education, 39(4), 365-384. doi:10.1023/a:1018785219220

Paulsen, M. B., \& Feldman, K. A. (2005). The Conditional and Interaction Effects of Epistemological Beliefs on the Self-Regulated Learning of College Students: Motivational Strategies. Research in Higher Education, 46(7), 731-768. Retrieved from http://www.jstor.org/stable/40197444

Schommer-Aikins, M. (2004). Explaining the Epistemological Belief System: Introducing the Embedded Systemic Model and Coordinated Research Approach. Educational Psychologist, 39(1), 19-29. doi:10.1207/s15326985ep3901_3

Schommer-Aikins, M., Bird, M., \& Bakken, L. (2010). Manifestations of an epistemological belief system in preschool to grade twelve classrooms. In L. D. Bendixen \& F. C. Feucht (Eds.), Personal Epistemology in the Classroom: Theory, Research, and Implications for Practice (pp. 31 54). Cambridge: Cambridge University Press.

Schommer-Aikins, M., Duell, O., \& Barker, S. (2003). Epistemological Beliefs Across Domains Using Biglan's Classification of Academic Disciplines. Research in Higher Education, 44(3), 347-366. doi:10.1023/a:1023081800014

Schommer-Aikins, M., Mau, W.-C., Brookhart, S., \& Hutter, R. (2000). Understanding Middle Students' Beliefs About Knowledge and Learning Using a Multidimensional Paradigm. The Journal of Educational Research, 94(2), 120-127. doi:10.1080/00220670009598750 
Schommer, M. (1993). Comparisons of beliefs about the nature of knowledge and learning among postsecondary students. Research in Higher Education, 34(3), 355-370. doi:10.1007/bf00991849

Schommer, M., \& Dunnell, P. A. (1997). Epistemological beliefs of gifted high school students. Roeper Review, 19(3), 153-156. doi:10.1080/02783199709553812

Schommer, M. A. (1989). The effects of beliefs about the nature of knowledge on comprehension. (Ph.D. Thesis), University of Illinois, Urbana-Champaign, Ann Arbor. Retrieved from https://vpn.utm.my/docview/303785974?accountid=41678 ProQuest Dissertations \& Theses Global database.

Tait, K. (2009). Understanding Tertiary Student Learning: Are They Independent Thinkers or Simply Consumers and Reactors? International Journal of Teaching and Learning in Higher Education, 21(1), 97-107. doi:https://files.eric.ed.gov/fulltext/EJ896248.pdf

Young, M. R. (2005). Personal Epistemological Beliefs And Their Relationship To Learning. Journal for Advancement of Marketing Education, 6(Spring), 63-76. Retrieved from http://www.mmaglobal.org/publications/JAME/JAME-Issues/JAME-2005-Vol06-Issue1/JAME2005-Vol06-Issue1-Young-pp63-76.pdf 